\title{
VIOLENCIA DE GÉNERO EXPERIMENTADA EN EL ÁMBITO ESCOLAR. UN ANÁLISIS DESCRIPTIVO DE LA ENCUESTA Nacional Sobre las Dinámicas de los Hogares, ENDIREH, PARA LAS ADOLESCENTES DE 15 A 19 AÑOS en el estado de Chiapas, MÉXico
}

\author{
GeNDER-BASED Violence in THE SCHOOL \\ Environment. A Descriptive Analysis of the \\ National Survey on Household Dynamics, \\ ENDireH, FOR AdOLESCENTS AGED 15 TO 19 \\ in the State of Chiapas, Mexico
} Angélica Aremy Evangelista García
Sarai Miranda Juárez

Resumen: Según Endireh 2016, 15.3\% de las adolescentes de 15 a 19 años en Chiapas que asisten o asistieron a la escuela en los últimos 12 meses sufrieron actos de violencia en su contra. La violencia sexual fue la más frecuente, 9.2\%; seguida por la violencia física, 6.6\%. La menos frecuente fue la violencia emocional, 5.5\%. En el marco del repunte de la violencia sexual que se registra en Endireh 2016, en comparación

\footnotetext{
* Doctora en Ciencias Sociales y Humanísticas por el Centro de Estudios Superiores de México y Centroamérica-Universidad de CIencias y Artes de Chiapas. Investigadora de El Colegio de la Frontera Sur adscrita al grupo académico Estudios de Género. Temas de interés: violencia de género, juventudes, derechos sexuales y reproductivos, VIH/SIDA, http://orcid.org/00000002-4460-854X, correo e.: aevangel@ecosur.mx.

** Doctora en Estudios de Población por El Colegio de México. Investigadora Cátedra Consejo Nacional de Ciencia y Tecnología, México, en El Colegio de la Frontera Sur adscrita al grupo académico Estudios de Género. Temas de interés: género, niñez, trabajo infantil, violencia, mercados de trabajo, http://orcid.org/0000-0003-1387-0497, correo e.: smiranda@ecosur.mx. Fecha de recepción: 0608 18; Fecha de aceptación: 311018.
}

(cc) EY-NC-ND Páginas 167-198. 
con Endireh 2011 donde este tipo de violencia aparecía en tercer lugar de incidencia, en este artículo analizaremos cómo se expresa la violencia en el ámbito escolar entre adolescentes de 15 a 19 años, quién perpetra este tipo de violencia en su contra, en cuáles lugares específicos del ámbito escolar y qué hacen las adolescentes en términos de solicitud de apoyo institucional o presentación de queja.

Palabras clave: violencia, género, análisis interseccional.

Abstract: According to National Survey on Household Dynamics, Endireh 2016, 15.3\% of adolescents aged 15 to 19 in Chiapas who attend or have attended school in the last 12 months have suffered acts of violence. Sexual violence was the most frequent, 9.2\%; followed by physical violence, $6.6 \%$. The least frequent was emotional violence, $5.5 \%$. In the context of rise in sexual violence registered in the Endireh 2016, compared to the Endireh 2011 where this type of violence appeared in third place of incidence, in this article we will analyze the following: how violence is expressed in the school environment among adolescents from 15 to 19 years old, who perpetrates this type of violence against them, in which specific places of the school environment and what adolescents do in terms of requesting institutional support or presenting a complaint.

Keywords: violence, gender, intersectional analysis.

\section{Introducción}

En este artículo proponemos abordar la amplia problemática de la violencia hacia las mujeres adolescentes — 15 a 17 años— en el ámbito escolar en Chiapas a partir de los resultados de la Encuesta Nacional sobre la Dinámica de las Relaciones en los Hogares, Endireh 2016. De manera particular queremos mostrar la gama variopinta de expresiones de la violencia que van desde actos frecuentes, sistemáticos, cotidianos, escurridizos, naturalizados y normalizados — denominados 
por diferentes autores como incivilidades, violencias pequeñas, microviolencias y micromachismos - hasta agresiones severas que son vistas como hechos excepcionales y aislados. Es decir, mostrar el continuum que implica conexiones entre las múltiples formas de violencia e incluso una escala en incremento de la gravedad de las mismas (ver Villela y Arenas, 2011; Mingo, 2013; Mingo y Moreno, 2015).

Adicionalmente, en el marco del repunte de la violencia sexual que se registra en Endireh 2016, en comparación con Endireh 2011 donde este tipo de violencia aparecía en tercer lugar de incidencia, analizaremos cómo se expresa la violencia en el ámbito escolar, quién la perpetra, en cuáles lugares específicos del ámbito escolar y qué hacen las adolescentes en términos de solicitud de apoyo institucional o presentación de queja.

Resulta muy importante garantizar a las adolescentes en Chiapas un ambiente escolar libre de violencia considerando los problemas de escolarización y asistencia que presenta la educación secundaria y media superior en el estado. Se ha documentado que las conductas violentas afectan la capacidad de concentración, la autoestima, el rendimiento y el éxito académico constituyéndose en factores de riesgo para el abandono escolar (Inegi, 2015). Aunque son diversos y complejos los factores que inciden en el abandono escolar, otras investigaciones muestran el papel de la violencia escolar, tanto entre pares como la perpetrada por autoridades escolares, como desencadenante en la decisión de abandonar la escuela sobre todo entre estudiantes de nuevo ingreso (SEP, 2013). En este sentido, la Encuesta Nacional sobre Exclusión, Intolerancia y Violencia (SEMS, 2014) muestra que los estudiantes de educación media superior que presentaron violencia recurrente registran un mayor ausentismo escolar. Es decir, el ausentismo es 30\% más elevado entre estudiantes que presentan episodios de violencia recurrente en tanto que reportan haber faltado dos o más veces al mes a la escuela.

Sólo para tener una idea sobre el aumento de la violencia en ámbitos escolares la Comisión Nacional de los Derechos Humanos, CNDH, reportó que en tan sólo dos años, es decir, de 2012 a 2014, el porcentaje 
del alumnado de educación básica que padeció algún tipo de bullying ${ }^{1}$ pasó de 30 a 40.2\% (CNDH, 2014).

En el estado de la cuestión elaborado por Frías (2012) se señala al estudio de Aguilera et al. de 1987 como uno de los primeros que arrojó resultados sobre violencia emocional y física a nivel nacional para alumnos y docentes de primaria y secundaria. Menciona que la Encuesta Nacional de Juventud 2005 también aporta información sobre la multiplicidad de relaciones violentas percibidas en el contexto escolar, pero no da cuenta del tipo de violencia, ni permite identificar las características del involucramiento de los y las jóvenes en dichas situaciones - agresor, víctima, víctima-agresor u observador- La misma encuesta de 2010 documenta experiencias individuales en lugar de percepciones sobre la situación de violencia en el ámbito educativo.

De manera más reciente, la Encuesta Nacional sobre Exclusión, Intolerancia y Violencia, ENEIVEMS (SEMS, 2014) muestra que a nivel medio superior $68.5 \%$ del alumnado ha experimentado algún tipo de violencia en el ámbito escolar por parte de sus pares. Los datos para Chiapas revelan que, durante los últimos 12 meses, $49 \%$ de los estudiantes varones había recibido algún insulto por parte de sus compañeros(as). Por su parte, $28 \%$ de las mujeres en Chiapas fueron insultadas en el contexto escolar.

Por otra parte, 54\% de los hombres en Chiapas ha sido objeto de algún apodo ofensivo y/o ridiculizante. Mientras que $17 \%$ de las mujeres fue objeto del mismo tipo de agresión. En relación con eventos violentos hacia las pertenencias u objetos personales de los

\footnotetext{
${ }^{1}$ Frecuentemente se generan confusiones entre el uso de los términos bullying y violencia en el ámbito escolar, sin embargo son prácticas con distintas características. Desde la literatura especializada se ha establecido que el principal criterio para diferenciar entre violencia y acoso escolar tiene que ver con la opción de respuesta dada por el estudiante cuando señala: "alguna vez", se interpreta como maltrato, como violencia; mientras que si se elige "con frecuencia" se categoriza como acoso escolar o bullying, es decir, "el carácter repetitivo, sistemático y la intencionalidad de causar daño o perjudicar a alguien que habitualmente es más débil son las principales características del acoso" (Castillo-Pulido, 2011: 418). La diferencia se acentúa más cuando se trata de violencia de género, cuyo centro nodal tiene que ver con el hecho de ser mujer o bien con el de portar características relacionadas con lo femenino. Si bien el bullying es una más de las expresiones de la práctica de la violencia en el ámbito escolar, no es el propósito de este trabajo profundizar al respecto.
} 
estudiantes, $28 \%$ de los varones dijo que le habían roto sus cosas; en tanto $7.6 \%$ de las mujeres sufrió un hecho similar por parte de otros(as) estudiantes.

En materia de violencia física entre los estudiantes de educación media superior, EMS, $14 \%$ de los hombres en Chiapas dijo que había recibido golpes durante los últimos 12 meses. Por su parte, $15 \%$ de las mujeres en Chiapas fue víctima de violencia física por parte de sus compañeros(as). Finalmente, $12 \%$ de las mujeres en Chiapas reporta haber recibido ofensas de carácter sexual, mientras que $14 \%$ de los hombres respondió que ha sido ofendido con insultos de carácter de este tipo.

De acuerdo con las cifras anteriormente mencionadas, las y los adolescentes están expuestos a diferentes formas de violencia - física, psicológica y sexual— en el ámbito escolar. Si bien México firmó la Convención sobre los Derechos del Niño donde se reconoce la condición de sujetos de derechos a niñas, niños y adolescentes, existe todavía una cultura de gran permisividad del ejercicio de violencia hacia este grupo de población. Esta justificación social se suma a la naturalización y normalización de la violencia hacia las adolescentes por su pertenencia al género femenino y a la ausencia de denuncias, resultando en un subregistro del fenómeno. En este sentido, nos interesa mostrar la expresión de los diferentes tipos de violencia cuando se perpetran con el propósito de reestablecer e imponer la subordinación de las mujeres y de lo femenino; es decir, cuando se trata de violencia de género.

Para los fines de este artículo, asumimos la definición que ONU da sobre violencia de género:

Todo acto de violencia basado en la pertenencia al sexo femenino, que tenga o pueda tener como resultado un daño o sufrimiento físico, sexual o psicológico para la mujer, así como amenazas de tales actos, la coerción o la privación arbitraria de la libertad, tanto si se producen en la vida pública como en la vida privada (ONU, 1994: 3).

Esta definición considera los actos que se ejercen contra las mujeres con el propósito de perpetuar su dominación y opresión por el hecho de ser 
mujeres, también incluye otras formas de violencia cuya motivación u origen no es el género. No obstante, la definición de Ward (2001, citado en Castro, 2012: 27) es más precisa en el sentido de que afirma que la violencia de género es aquella que "explota la distinción culturalmente establecida entre hombres y mujeres, es decir, es violencia que se ejerce para reforzar dicha diferencia, o para restablecerla, o para imponerla"; por lo tanto, se perpetra entre hombres, contra mujeres de todas las edades y personas LGBT a quienes se impone el predominio de la heterosexualidad y los estereotipos de género.

La adolescencia, etapa de la vida a la que pertenecen las mujeres de interés para este trabajo, se ha estudiado ampliamente desde la perspectiva de la psicología y la ciencia médica. Identificándola como "una etapa de cambios físicos, cognoscitivos y emocionales que constituye el crecimiento de la niñez a la edad adulta" (Álvarez y Vallejo, 2002: 95). Otras disciplinas como la sociología y la antropología han dado cuenta de la adolescencia como un periodo de transición (Arias-Gallegos, 2013) o bien como un proceso en que las personas pasan de la niñez hacia la adultez joven. Algunos autores la clasifican en tres principales etapas:

la adolescencia temprana que va de los 10 a 13 años caracterizada por el desarrollo físico y que se conoce como pubertad, la adolescencia media que va de los 14 a 16 ańos, y se caracteriza por un distanciamiento de la familia y la adolescencia tardía entre los 17 y 19 años en la que se termina de formar la identidad (Ayala-Carrillo, 2015: 495).

Este proceso es decisivo para la reestructuración y consolidación de la imagen corporal, la independencia y la autonomía económica y social, el establecimiento de la identidad, y la adopción de un sistema de valores determinantes para su futuro (ibídem).

Por ello, en el presente artículo se considera la importancia de analizar la violencia de género que experimentan las adolescentes de 15 a 19 años en el ámbito escolar, pues representa una etapa de la vida en la que ejercer o recibir violencia puede llegar a marcar los procesos identitarios y de adopción de valores. Lo que se conjuga con una fundamental importancia del análisis del ámbito escolar, ya que es justo en ese 
espacio de socialización donde las adolescentes escolarizadas pasan una importante parte de su tiempo y tienen la oportunidad de experimentar interrelaciones mediadas por prácticas como la violencia. En el espacio escolar hay altas posibilidades de que las adolescentes aprendan e introyecten la violencia como algo natural y cotidiano (ibídem).

\section{Metodología}

Los datos que se utilizan para este trabajo provienen de la más reciente Encuesta Nacional sobre la Dinámica de las Relaciones en los Hogares, Endireh, 2016, levantada por el Instituto Nacional de Estadística y Geografía.

Endireh recoge información que permite conocer y analizar la magnitud de la violencia contra las mujeres de 15 y más años con representatividad a nivel nacional y por entidad federativa. Se enfoca en diversos ámbitos que incluyen el espacio escolar (Inegi, 2017).

El análisis que se realiza es de tipo descriptivo y comparativo, ${ }^{2}$ a partir de 233,166 mujeres adolescentes de 15 a 19 años, 97.2\%, que alguna vez asistieron a la escuela en Chiapas; y de 134,499 mujeres adolescentes de 15 a 19 ańos, 57.7\%, que reportó haber asistido a la escuela durante los últimos 12 meses.

La encuesta provee información valiosa para poner en perspectiva las distintas manifestaciones de la violencia de género contra las adolescentes en el ámbito escolar, sin embargo, como todas las encuestas de hogares, al momento de desagregar la información se reduce la muestra, lo que representa una de las mayores limitaciones para realizar un análisis concluyente y con suficiente representatividad estadística. ${ }^{3}$

\footnotetext{
${ }^{2}$ El Teorema del Limite Central afirma que "si una muestra es lo bastante grande — generalmente cuando (n) supera los 30 casos-, sea cual sea la distribución de la media muestral, seguirá aproximadamente una distribución normal" (Wackerly, Medndenhall y Scheaffer, 2002: 34), aceptando como válido el análisis estadístico, en tanto que para el estado de Chiapas la muestra sin expandir con la que se construyó el análisis corresponde a 331 mujeres de 15 a 19 ańos.

${ }^{3}$ Un ejemplo de ello es la desagregación a partir de ciertas categorías. Por ejemplo, al desagregar la muestra sin expandir para el estado de Chiapas - 331 mujeres de 15 a 19 años- por condición indígena resultan 130 casos, si esto a su vez lo volvemos a desagregar por estado conyugal entonces quedan 32 casos. En otras palabras, sólo hay 32 registros de adolescentes hablantes de alguna lengua indígena y que además están unidas. Ello desagregado por edad, resulta en 2, 5 , 4, 11 y 10 casos, respectivamente, para cada ańo en el intervalo de 15 a 19 ańos. Lo anterior es una limitación importante para efectos de buscar la interrelación de estas variables.
} 
Para efectos del análisis descriptivo en el que se focaliza en las distribuciones porcentuales de las diferentes manifestaciones de violencia de género, se realizó la prueba chi cuadrada con el fin de corroborar la significancia estadística de cada una de las dimensiones que se utilizan (Anexo 1 y 2, al final del documento).

\section{Análisis}

De inicio cabe señalar que en la entidad menos de seis de cada diez adolescentes, $57.7 \%$, asistió a la escuela en el último ańo, mientras que a nivel nacional asistieron siete de cada diez, 73.3\%. Según los datos que arroja Endireh, Chiapas es el estado donde se registra el más bajo porcentaje de asistencia a la escuela en el último ańo, seguido por Michoacán de Ocampo, 64.15\%; Guanajuato, 68.29\%; Zacatecas, $68.56 \%$, y Oaxaca, 68.90\%.

De las adolescentes entre 15 y 19 años que asistieron a la escuela, $15.3 \%$ ha sufrido algún incidente de violencia en los últimos 12 meses, siendo la violencia sexual, 9.2\%, la que más alto porcentaje registra, seguida por la violencia física, 6.6\%, y la emocional, 5.5\%. Cifras por debajo del promedio nacional para el mismo rango de edad y periodo de referencia, donde $20.7 \%$ ha sufrido algún incidente de violencia: también la más frecuente es la violencia sexual, $12.4 \%$, seguida por la violencia física, $9.3 \%$, y la violencia emocional, $8.3 \%$.

Sin embargo, cuando el periodo de referencia es a lo largo de la vida, el porcentaje de las adolescentes entre 15 y 19 años que han sufrido algún incidente de violencia en el ámbito escolar se incrementa a 18.5\%; por lo tanto, se incrementan también los porcentajes de violencia física, 9.4\%, así como los de la sexual, 9.4\%, y emocional, 6.7\% (cuadro 1). Se infiere entonces que la violencia se da en todos los niveles educativos con una mayor presencia de la violencia física en los primeros años de escolaridad en tanto que muestra un incremento de casi tres puntos porcentuales.

En todo caso, ambas cifras se encuentran por arriba de $13.6 \%$ del conjunto de mujeres de 15 años y más en Chiapas que han sufrido algún tipo de violencia en el último año en el ámbito escolar, donde también la violencia sexual es la más frecuente, 9.3\%, seguida por la 
violencia emocional, 6.2\%, y la violencia física, 5.7\%. A continuación, analizaremos los tres tipos de violencia según su incidencia entre las adolescentes de Chiapas:

\begin{tabular}{|c|c|c|c|c|c|c|c|c|c|c|}
\hline & \multicolumn{5}{|c|}{ Últimos 12 meses } & \multicolumn{5}{|c|}{ A lo largo de la vida } \\
\hline & $\begin{array}{c}\text { Sin } \\
\text { incidentes }\end{array}$ & \multicolumn{4}{|c|}{ Con incidentes de violencia ${ }^{1}$} & $\begin{array}{c}\text { Sin } \\
\text { incidentes }\end{array}$ & \multicolumn{4}{|c|}{ Con incidentes de violencia ${ }^{1}$} \\
\hline & & \multicolumn{4}{|c|}{ Tipo de violencia } & & \multicolumn{4}{|c|}{ Tipo de violencia } \\
\hline & & Total $^{2}$ & Emocional & Física & Sexual & & Total $^{2}$ & Emocional & Física & Sexua \\
\hline Chiapas & 84.7 & 15.3 & 5.5 & 6.6 & 9.2 & 81.5 & 18.5 & 6.7 & 9.4 & 9.4 \\
\hline \begin{tabular}{|l} 
Estados \\
Unidos \\
Mexicanos
\end{tabular} & 79.3 & 20.7 & 8.3 & 9.3 & 12.4 & 70.3 & 29.7 & 12 & 18.5 & 16.9 \\
\hline
\end{tabular}

${ }^{1}$ Mujeres que declararon haber padecido al menos un incidente de violencia por parte de alguna persona en el ámbito escolar.

${ }^{2}$ La suma de los tipos de violencia no coincide con el total, pues cada mujer pudo haber padecido más de uno.

Fuente: Cálculos propios a partir de la Encuesta Nacional sobre la Dinámica de las Relaciones en los Hogares,

Endireh, 2016. Instituto Nacional de Estadística y Geografía

\section{Violencia sexual}

La Ley General de Acceso de las Mujeres a una Vida Libre de Violencia, LGAMVLV, en su artículo 6 define la violencia sexual como "cualquier acto que degrada o dańa el cuerpo y/o la sexualidad de la víctima y que por tanto atenta contra su libertad, dignidad e integridad física. Es una expresión de abuso de poder que implica la supremacía masculina sobre la mujer, al denigrarla y concebirla como objeto" (DOF, 2009). En este sentido, Endireh 2016 registra cuatro subtipos de violencia sexual, siendo el más frecuente la intimidación sexual, 7.9\%; seguido por el acoso sexual/hostigamiento sexual, ${ }^{4} 3.1 \%$; el abuso sexual, $1 \%$, y la violación o intento de violación, $0.4 \%$.

Son cuatro las principales prácticas de violencia sexual de las que son víctimas las adolescentes y corresponden con tres actos de intimidación

\footnotetext{
${ }^{4}$ En el artículo 13 de LGAMVLV se establece la diferencia entre hostigamiento y acoso sexual. Así, se dice que ambos se expresan en conductas verbales, físicas o ambas, relacionadas con la sexualidad de connotación lasciva y constituyen el ejercicio del poder en los ámbitos laboral y escolar. En el hostigamiento existe una relación de subordinación real de la víctima frente al agresor, mientras que en el acoso no existe tal relación de subordinación pero el ejercicio de poder conlleva a un estado de indefensión y de riesgo para la víctima (DOF, 2009).
} 
sexual y uno de acoso/hostigamiento sexual. La práctica más frecuente, $5.8 \%$, de violencia sexual es haber recibido mensajes o comentarios publicados con "insinuaciones sexuales, insultos u ofensas, a través del celular, correo electrónico o redes sociales — como Facebook, Twitter, WhatsApp_-”. La frecuencia de esta práctica disminuye entre las adolescentes del mismo rango de edad a lo largo de la vida como periodo de referencia, 3.4\%. Por lo tanto, probablemente este 5.8\% en el último año se corresponde con el mayor uso de las tecnologías de información en este rango de edad y explica que los principales agresores sexuales de las adolescentes sean sus compañeros, $53.3 \%$, seguidos por los maestros, $41.7 \% .5^{5}$ Otras prácticas de intimidación sexual de las que han sido víctimas las adolescentes en Chiapas son: "le han hecho sentido sentir miedo de ser atacada o abusada sexualmente", 2.9\%; y "le han dicho piropos groseros u ofensivos de tipo sexual o sobre su cuerpo", 2.4\%. Una práctica registrada con una considerable frecuencia hacia las adolescentes en Chiapas, del subtipo de acoso o hostigamiento sexual, consiste en propuestas o insinuaciones de "tener relaciones sexuales a cambio de calificaciones, cosas o beneficios en la escuela", 3.1\% (cuadro 2).

$\mathrm{Al}$ agrupar las prácticas de violencia sexual hacia las mujeres en el ámbito escolar referidas en Endireh a partir de su severidad podríamos construir una suerte de escala y calificar las prácticas de intimidación sexual como leves, las de acoso y hostigamiento sexual como moderadas, y las de abuso sexual, violación e intento de violación como graves, a partir de considerar en el acto la sustitución de la "fuerza ilocucionaria” por la fuerza física de la persona agresora (Mingo y Moreno, 2015).

A decir de Mingo y Moreno (2015: 143, 148), la fuerza ilocucionaria hace referencia a "la fuerza de la palabra sostenida en el poder de la institución social” a manera de actos de habla cuya emisión es, de

\footnotetext{
${ }^{5}$ La población entre 12 y 17 años constituye el segundo grupo, a nivel nacional, que más acceso y uso tiene de las tecnologías de información y comunicación, TIC, 19.3\%. En el estado de Chiapas es, incluso, el grupo de población que más las usa, 27.7\%. Adicionalmente, por escolaridad, los principales usuarios de internet en Chiapas tienen preparatoria, 29.1\%. También destaca el uso que en general se le da a las TIC para acceder a las redes sociales, principales plataformas donde se registran diversas formas de violencia. Así, en Chiapas 63.2\% utiliza las TIC para acceder a las redes (Inegi, 2016).
} 
manera explícita y directa, una acción. Así entonces, "si un acto sexista no se interpreta como tal, no tiene fuerza ilocucionaria: cae en el vacío y deja de tener sentido social. La razón de ser del acto sexista es la instauración o la restauración de un orden". Por lo tanto, cuando la adolescente a la que va dirigido el acto no capta este sentido, se considera un acto fallido. Así, podemos considerar que en la medida de que las adolescentes reportan estas prácticas de violencia captaron su sentido.

A partir de esta escala de severidad encontramos que las prácticas leves o de "baja intensidad" (Castro y Vázquez, 2008) son las más frecuentes pero también cotidianas, escurridizas y reiterativas; por lo tanto, están naturalizadas y hasta normalizadas además de cumplir su función de reproducir las jerarquías de género y de someter a las adolescentes (Villela y Arenas, 2011; Mingo, 2013; Mingo y Moreno, 2015). Por otra parte, el abuso sexual y la violación e intento de violación considerados actos graves son los menos frecuentes, afortunadamente para ese grupo de edad no se registran violaciones pero sí intentos de obligarlas a tener relaciones sexuales en contra de su voluntad, $0.4 \%$.

En términos de intimidación sexual y abuso sexual, las adolescentes de Chiapas presentan porcentajes menores respecto al nivel nacional. Sin embargo, en materia de acoso sexual/hostigamiento sexual registran mayor porcentaje a lo largo de la vida, $2.1 \%$, respecto al nivel nacional, $1.2 \%$, y un porcentaje cuatro veces superior, $3.1 \%$ vs. $0.7 \%$, cuando el periodo de referencia es el último año. Además, destaca que, a diferencia de lo que sucede a nivel nacional, en Chiapas es mayor el porcentaje para el último ańo como periodo de referencia, mostrando mayor presencia de este tipo de violencia en los niveles educativos superiores. Respecto a violación e intento de violación, las adolescentes en Chiapas presentan los mismos porcentajes que a nivel nacional; esto es, $0.6 \%$ a lo largo de la vida, y $0.4 \%$ en el último año (cuadro 2). 
Cuadro 2. Distribución de adolescentes de 15 a 19 por condición, tipo, clase y situación de violencia sexual en el ámbito escolar según periodo de referencia en Chiapas y a nivel nacional, 2016

\begin{tabular}{|c|c|c|c|c|}
\hline \multirow{3}{*}{ Condición, tipo, clase y situación de violencia sexual } & \multicolumn{2}{|c|}{ CHIAPAS } & \multicolumn{2}{|c|}{$\begin{array}{l}\text { ESTADOS UNIDOS } \\
\text { MEXICANOS }\end{array}$} \\
\hline & \multicolumn{4}{|c|}{ Periodo de referencia } \\
\hline & $\begin{array}{l}\text { A lo largo de } \\
\text { la vida }\end{array}$ & \begin{tabular}{|l|} 
En los \\
últimos \\
doce meses
\end{tabular} & $\begin{array}{l}\text { A lo largo de } \\
\text { la vida }\end{array}$ & $\begin{array}{l}\text { En los } \\
\text { últimos } \\
\text { doce meses }\end{array}$ \\
\hline Violencia sexual & 9.4 & 9.2 & 16.9 & 12.4 \\
\hline Intimidación sexual & 7.7 & 7.9 & 15 & 11.1 \\
\hline $\begin{array}{l}\text { Le han hecho sentir miedo de ser atacada o abusada } \\
\text { sexualmente }\end{array}$ & 3.4 & 2.9 & 3.6 & 1.8 \\
\hline $\begin{array}{l}\text { Le han dicho piropos groseros u ofensivos de tipo sexual } \\
\text { o sobre su cuerpo }\end{array}$ & 2.8 & 2.4 & 9.3 & 6.8 \\
\hline $\begin{array}{l}\text { Le han enviado mensajes o publicado comentarios con } \\
\text { insinuaciones sexuales, insultos u ofensas, a través del } \\
\text { celular, correo electrónico o redes sociales (como } \\
\text { Facebook, Twitter, WhatsApp) }\end{array}$ & 3.4 & 5.8 & 7.8 & 6.1 \\
\hline Acoso sexual / Hostigamiento sexual & 2.1 & 3.1 & 1.2 & 0.7 \\
\hline $\begin{array}{l}\text { Le han propuesto o insinuado tener relaciones sexuales } \\
\text { a cambio de calificaciones, cosas o beneficios en la } \\
\text { escuela }\end{array}$ & 2.1 & 3.1 & 1.1 & 0.6 \\
\hline $\begin{array}{l}\text { La castigaron, trataron mal o se vengaron, porque se } \\
\text { negó a tener relaciones sexuales (la reprobaron, le } \\
\text { bajaron la calificación, la expulsaron o sacaron de la } \\
\text { escuela, etc.) }\end{array}$ & 0.3 & 0.5 & 0.4 & 0.3 \\
\hline Abuso sexual & 2.1 & 1 & 5.8 & 3.5 \\
\hline $\begin{array}{l}\text { Alguna persona le mostró sus partes íntimas o se las } \\
\text { manoseó enfrente de usted }\end{array}$ & 0.5 & 0.9 & 1.7 & 0.7 \\
\hline $\begin{array}{l}\text { La han obligado a mirar escenas o actos sexuales o } \\
\text { pornográficos (fotos, revistas, vídeos o películas } \\
\text { pornográficas) }\end{array}$ & 0 & 0 & 0.4 & 0.2 \\
\hline $\begin{array}{l}\text { La han manoseado, tocado, besado o se le han arrimado, } \\
\text { recargado o encimado sin su consentimiento }\end{array}$ & 1.5 & 0.9 & 4.8 & 3 \\
\hline Violación e intento de violación & 0.6 & 0.4 & 0.6 & 0.4 \\
\hline $\begin{array}{l}\text { Han tratado de obligarla a tener relaciones sexuales en } \\
\text { contra de su voluntad }\end{array}$ & 0.6 & 0.4 & 0.6 & 0.4 \\
\hline $\begin{array}{l}\text { La han obligado a tener relaciones sexuales en contra de } \\
\text { su voluntad }\end{array}$ & 0 & 0 & 0.1 & 0.1 \\
\hline
\end{tabular}

Fuente: Cálculos propios a partir de la Encuesta Nacional sobre la Dinámica de las Relaciones en los Hogares (ENDIREH) 2016. Instituto Nacional de Estadística y Geografía 


\section{Violencia física}

La violencia física es definida en el artículo 6 de LGAMVLV como "cualquier acto que inflige daño no accidental, usando la fuerza física o algún tipo de arma u objeto que pueda provocar o no lesiones ya sean internas, externas, o ambas" (DOF, 2009). En este sentido, a la mayoría de las adolescentes las "han pellizcado, jalado el cabello, empujado, jaloneado, abofeteado o aventado algún objeto", 5.6\%, seguido de por quienes las "han pateado o golpeado con el puño", 2.2\%, en el último año en el ámbito escolar. Son sus compañeros los principales perpetradores de la violencia física, 58.4\%, y siguen las compañeras, 41.6\%; por lo que se trata sin duda de un tipo de violencia entre pares, es decir, entre iguales (cuadro 5). Resulta difícil sólo con estos datos concluir que la violencia física hacia las mujeres entre pares perpetrada por ambos sexos es violencia de género; sin embargo, no debemos menospreciar que sean los compañeros los principales agresores.

Los porcentajes de ambas prácticas de violencia física se incremen$\tan , 7.7 \%$ y $3.2 \%$, respectivamente, cuando el periodo de referencia es a lo largo de la vida; esto es, cuando se abarcan incidentes de violencia experimentados durante la infancia en el ámbito escolar. Para este periodo de referencia incluso se registra un bajo porcentaje, 1\%, de las que han sido atacadas o agredidas "con un cuchillo, navaja o arma de fuego"; práctica ausente entre las adolescentes para el último año. Además, durante este periodo de referencia, se suman los maestros, $14.4 \%$, a los compañeros, 54\%, y las compañeras, 28\%, como perpetradores de violencia física (cuadro 5).

Respecto al nivel nacional, los porcentajes para los diferentes actos de violencia física entre las adolescentes en Chiapas en el ámbito escolar son bajos, a excepción de para las que las han pateado o golpeado con el puño en el último año donde se registra el mismo porcentaje de las adolescentes en Chiapas como a nivel nacional, 2.2\%. Más adolescentes en Chiapas, $1 \%$, que a nivel nacional, $0.6 \%$, dicen que las han atacado o agredido con un cuchillo, navaja o arma de fuego a lo largo de la vida (cuadro 3).

La magnitud de este tipo de violencia y el hecho de que sea perpetrada principalmente entre pares en el periodo de referencia del último 
año nos obliga a preguntarnos por su significación. Diversas investigaciones cualitativas han referido la violencia entre jóvenes como un modo de sociabilidad lúdica, de "llevarse y aguantarse", lo cual reduce la posibilidad de que sea visibilizada como incivilidades (di Napoli, 2018). De ahí la importancia de identificar "los comportamientos, contextos y circunstancias por las cuales una situación deja de ser un juego para ser percibida como ofensiva" (ídem: 18).

El importante porcentaje de mujeres adolescentes en Endireh que usan la violencia física contra otras adolescentes, $41.6 \%$ en el último año y $28 \%$ a lo largo de la vida, nos remite al estado de la cuestión elaborado por di Napoli donde entre mujeres se registran "violencias de tipo más relacional expresadas en formas de exclusión o agresiones verbales", mientras el uso de la violencia física "está más presente en aquellas escuelas que reciben alumnos de sectores populares" (ídem: 21-22). Así entonces, sería necesario un análisis de los resultados de Endireh 2016 que considere el nivel socioeconómico de las adolescentes para complejizar el análisis de la frecuencia de la violencia física entre mujeres adolescentes.

Cuadro 3. Distribución de adolescentes de 15 a 19 por condición, tipo, clase y situación de violencia física en el ámbito escolar según periodo de referencia en Chiapas y a nivel nacional, 2016.

\begin{tabular}{|l|c|c|c|c|}
\hline \multirow{2}{*}{$\begin{array}{l}\text { Condición, tipo, clase y situación } \\
\text { de violencia física }\end{array}$} & \multicolumn{3}{|c|}{ Chiapas } & \multicolumn{2}{c|}{$\begin{array}{c}\text { Estados Unidos } \\
\text { Mexicanos }\end{array}$} \\
\cline { 2 - 5 } & $\begin{array}{c}\text { A lo largo de } \\
\text { la vida }\end{array}$ & $\begin{array}{c}\text { En los } \\
\text { últimos doce } \\
\text { meses }\end{array}$ & $\begin{array}{c}\text { A lo largo de } \\
\text { la vida }\end{array}$ & $\begin{array}{c}\text { En los } \\
\text { umos doce } \\
\text { meses }\end{array}$ \\
\hline Violencia física & $\mathbf{9 . 4}$ & $\mathbf{6 . 6}$ & $\mathbf{1 8 . 5}$ & $\mathbf{9 . 3}$ \\
\hline $\begin{array}{l}\text { La han pellizcado, jalado el cabello, } \\
\text { empujado, jaloneado, abofeteado o } \\
\text { aventado algún objeto }\end{array}$ & 7.7 & 5.6 & 17.1 & 8.5 \\
\hline $\begin{array}{l}\text { La han pateado o golpeado con el } \\
\text { puño }\end{array}$ & 3.2 & 2.2 & 5.4 & 2.2 \\
\hline $\begin{array}{l}\text { La han atacado o agredido con un } \\
\text { cuchillo, navaja o arma de fuego }\end{array}$ & 1 & 0 & 0.6 & 0.2 \\
\hline
\end{tabular}

Fuente: Cálculos propios a partir de la Encuesta Nacional sobre la Dinámica de las Relaciones en los Hogares, Endireh, 2016. Instituto Nacional de Estadística y Geografía 


\section{Violencia emocional}

Según se establece en el artículo 6 de LGAMVLV, cuando el acto u omisión consiste en "negligencia, abandono, descuido reiterado, celotipia, insultos, humillaciones, devaluación, marginación, indiferencia, infidelidad, comparaciones destructivas, rechazo, restricción a la autodeterminación y amenazas" (DOF, 2009) que dañan la estabilidad psicológica y ocasionan depresión, aislamiento, devaluación de la autoestima e incluso el suicidio, estamos hablando de violencia psicológica o emocional.

Aunque la violencia emocional hacia las adolescentes en el último año es la menos frecuente, $6.7 \%$, se manifiesta principalmente en ofensas o humillaciones por el hecho de ser mujer: "la hicieron sentir menos o mal”, $2.6 \%$, y en "comentarios ofensivos acerca de que las mujeres no deberían estudiar", 2.5\%. Más de la mitad, 55\%, de los perpetradores son principalmente hombres: compañeros, $38.1 \%$, y maestros, $16.9 \%$; llama la atención que también son agredidas por personas desconocidas de la escuela, $36.7 \%$, y en menor proporción por sus compañeras, $8.3 \%$ (cuadro 4). En este caso, claramente se trata de violencia de género en tanto que las manifestaciones antes mencionadas tienen el propósito de imponer la subordinación y opresión de lo femenino.

Cuadro 4. Distribución de adolescentes de 15 a 19 por condición, tipo, clase y situación de violencia emocional en el ámbito escolar según periodo de referencia en Chiapas y a nivel nacional, 2016.

\begin{tabular}{|c|c|c|c|c|}
\hline \multirow{3}{*}{$\begin{array}{l}\text { Condición, tipo, clase y situación de } \\
\text { violencia emocional }\end{array}$} & \multicolumn{2}{|c|}{ Chiapas } & \multicolumn{2}{|c|}{$\begin{array}{l}\text { Estados Unidos } \\
\text { Mexicanos }\end{array}$} \\
\hline & \multicolumn{4}{|c|}{ Periodo de referencia } \\
\hline & $\begin{array}{c}\text { A lo largo de } \\
\text { la vida }\end{array}$ & $\begin{array}{c}\text { En los } \\
\text { últimos doce } \\
\text { meses } \\
\end{array}$ & $\begin{array}{c}\text { A lo largo de } \\
\text { la vida }\end{array}$ & $\begin{array}{c}\text { En los } \\
\text { últimos doce } \\
\text { meses }\end{array}$ \\
\hline Violencia emocional & 6.7 & 5.5 & 12 & 8.3 \\
\hline Degradación / Acoso emocional & 5.9 & 4.6 & 10 & 6.8 \\
\hline $\begin{array}{l}\text { La han ofendido o humillado por el } \\
\text { hecho de ser mujer (la hicieron sentir } \\
\text { menos o mal) }\end{array}$ & 1.5 & 2.6 & 4 & 2.5 \\
\hline $\begin{array}{l}\text { La han ignorado o no la han tomado en } \\
\text { cuenta por ser mujer }\end{array}$ & 0.7 & 0 & 3.7 & 2.4 \\
\hline $\begin{array}{l}\text { Le han hecho comentarios ofensivos } \\
\text { acerca de que las mujeres no deberían } \\
\text { estudiar }\end{array}$ & 4.5 & 2.5 & 6.2 & 4 \\
\hline Intimidación y acecho & 1.6 & 0.9 & 3.7 & 2.3 \\
\hline $\begin{array}{l}\text { La han vigilado o seguido al salir de la } \\
\text { escuela }\end{array}$ & 1.6 & 0.9 & 3.7 & 2.3 \\
\hline
\end{tabular}

Fuente: Cálculos propios a partir de la Encuesta Nacional sobre la Dinámica de las

Relaciones en los Hogares, Endireh, 2016. Instituto Nacional de Estadística y Geografía 
Cuando el periodo de referencia es a lo largo de la vida, las adolescentes refieren como sus principales fuentes de violencia emocional a personas desconocidas de la escuela, $37.6 \%$, y a las compañeras, $22.6 \%$, le siguen en un segundo plano los compañeros, $19.1 \%$, y los maestros, $13.1 \%$ (cuadro 5).

Cuadro 5. Distribución del total de agresores mencionados por las adolescentes de 15 a 19 años que experimentaron violencia en el ámbito escolar por tipo de agresor según periodo de referencia y tipo de violencia en Chiapas, 2016.

\begin{tabular}{|l|r|r|r|r|r|r|r|r|}
\hline & \multicolumn{7}{|c|}{ Periodo de referencia y tipo de violencia } \\
\cline { 2 - 10 } \multicolumn{1}{|c|}{ Agresor } & \multicolumn{7}{|c|}{ A lo largo de la vida } & \multicolumn{3}{c|}{ Últimos 12 meses } \\
\cline { 2 - 10 } & Total & Emocional & Física & Sexual & Total & Emocional & Física & Sexual \\
\hline $\begin{array}{l}\text { Total de agresores } \\
\text { mencionados }\end{array}$ & 100 & 100 & 100 & 100 & 100 & 100 & 100 & 100 \\
\hline Maestro & 16.6 & 13.1 & 14.4 & 19.5 & 21.6 & 16.9 & 0 & 41.7 \\
\hline Maestra & 0.5 & 0 & 1.2 & 0 & 0 & 0 & 0 & 0 \\
\hline Compañero & 46.2 & 19.1 & 54 & 48.2 & 51.1 & 38.1 & 58.4 & 53.3 \\
\hline Compañera & 17.4 & 22.6 & 28 & 7.2 & 15.9 & 8.3 & 41.6 & 0 \\
\hline $\begin{array}{l}\text { Director(a) } \\
\text { Trabajador de la } \\
\text { escuela }\end{array}$ & 1.1 & 0 & 0 & 0 & 0 & 0 & 0 & 0 \\
\hline $\begin{array}{l}\text { Trabajadora de la } \\
\text { escuela }\end{array}$ & 0.9 & 0 & 0 & 2.3 & 0 & 0 & 0 & 0 \\
\hline $\begin{array}{l}\text { Persona desconocida } \\
\text { de la escuela }\end{array}$ & 12.9 & 37.6 & 2.5 & 13.8 & 9.3 & 36.7 & 0 & 0 \\
\hline $\begin{array}{l}\text { Otra persona de la } \\
\text { escuela }\end{array}$ & 4.4 & 7.6 & 0 & 7 & 0 & 0 & 0 & 0 \\
\hline No especificado & 0 & 0 & 0 & 2 & 2.1 & 0 & 0 & 5 \\
\hline
\end{tabular}

Fuente: Cálculos propios a partir de la Encuesta Nacional sobre la Dinámica de las Relaciones en los Hogares, Endireh, 2016. Instituto Nacional de Estadística y Geografía

Nuevamente los porcentajes que registran las adolescentes en Chiapas son menores a los que registran sus pares a nivel nacional. Destaca que las adolescentes en Chiapas reportan un porcentaje ligeramente mayor en "las han ofendido o humillado por el hecho de ser mujer — las hicieron sentir menos o mal-", $2.6 \%$, respecto a las adolescentes a nivel nacional, 2.5\%, para el último año.

Podríamos interpretar estas experiencias de violencia emocional como expresión del proyecto social de domesticación al que están sujetas niñas y adolescentes y que, a decir de Castro y Vázquez (2008), inicia 
tempranamente en sus vidas. Es decir, se trata de un "entrenamiento" de género en particular que inculca y desarrolla un habitus ${ }^{6}$ que predispone al sometimiento y la constante devaluación por ser mujeres e incluso configura una suerte de ideario y código de conducta compuesto por un conjunto de prácticas reprimidas y normas interiorizadas (ibídem). La domesticación empieza en la familia, y contribuyen a la misma otras instituciones. Así, en su tránsito por el ámbito escolar son socializadas y sometidas a las reglas de dominación masculina.

\section{Estado conyugal, hablantes de lengua indígena y escolaridad}

No es propósito de este apartado enlistar todas las desigualdades posibles que afectan a las adolescentes en Chiapas, sino de fijarse en cómo el estado conyugal, ${ }^{7}$ ser hablante de lengua indígena, ${ }^{8}$ y la escolaridad en tanto categorías sociales que mantienen relaciones recíprocas con el género, estructuran de manera diferencial las experiencias de violencia que experimentan las adolescentes en el ámbito escolar. En este sentido, nos proponemos superar la conceptualización de las adolescentes como sujetos únicos, universales y homogéneos, y considerarlas plurales, complejas, atravesadas y, por tanto, interseccionadas (Platero, 2014).

Asumimos, entonces, en la medida que la muestra tomada de Endireh lo permite, una perspectiva de análisis interseccional que reconoce el

\footnotetext{
${ }^{6}$ Entendido como "Los acondicionamientos asociados a una clase particular de condiciones de existencia ... sistemas de disposiciones duraderas y transferibles, estructuras estructuradas predispuestas para funcionar como estructuras estructurantes, es decir, como principios generadores y organizadores de prácticas y representaciones que pueden estar objetivamente adaptadas a su fin sin suponer la búsqueda consciente de fines y el dominio expreso de las operaciones necesarias para alcanzarlos, objetivamente 'reguladas' y 'regulares' sin ser el producto de la obediencia a reglas, $y$, a la vez que todo esto, colectivamente orquestadas sin ser producto de la acción organizadora de un director de orquesta” (Bourdieu, 1991: 92, citado en Martínez, 2017: 2 ).

${ }^{7}$ Según el glosario de Endireh se refiere a la "situación de las personas en relación a la unión o matrimonio de acuerdo con las leyes o costumbres del país". En la Encuesta "se identifican dos grandes grupos las casadas o unidas actualmente y aquellas que no lo están, siendo estas separadas, divorciadas, viudas y solteras" (ver Inegi, 2017).

${ }^{8}$ Según el criterio restringido utilizado para la cuantificación de la población indígena, ésta se mide mediante la adscripción relacionada con el habla de la lengua. De ahí que nos permita una aproximación a la condición de las adolescentes indígenas.

${ }_{9}^{9}$ Desde una revisión crítica a la interseccionalidad, Sales (2017: 252) afirma que "no hay consenso en el significado de la 'intersección', de las diferentes 'categorías o divisiones sociales' que interactúan, ni en la perspectiva metodológica a seguir para analizar dichas intersecciones”.
} 
carácter relacional y complejo de la realidad social. Es decir, en tanto que diferentes relaciones de poder localizan a los individuos o grupos sociales y esta localización produce situaciones de vulnerabilidad, las violencias hacia las adolescentes no pueden ser aprehendidas desde el género como única categoría social de opresión y discriminación. Por lo tanto, consideramos las tres categorías sociales antes mencionadas para aproximarnos a un enfoque de urdimbre, entretrama, imbricación y consustancialidad, para con ello expresar la noción de inseparabilidad de las categorías sociales (Dunezat, 2017).

Así, en cuanto al estado conyugal, tanto en Chiapas como a nivel nacional el mayor porcentaje de adolescentes que son víctimas de violencia en el ámbito escolar en el último año era la de soltera, $91.6 \%$ y $95.9 \%$, respectivamente (cuadro 6). Además, en Chiapas $66.3 \%$ de estas adolescentes solteras tenía estudios de nivel medio superior, seguidas por las que contaban con estudios secundarios, $33.7 \%$.

Cuadro 6. Distribución de adolescentes de 15 a 19 años por estado conyugal según condición y tipo de violencia en el ámbito escolar en los últimos 12 meses en Chiapas y a nivel nacional, 2016.

\begin{tabular}{|c|c|c|c|c|c|c|c|c|}
\hline \multirow{3}{*}{$\begin{array}{l}\text { Estado } \\
\text { conyugal }\end{array}$} & \multicolumn{8}{|c|}{ Condición de violencia } \\
\hline & \multicolumn{4}{|c|}{ Chiapas } & \multicolumn{4}{|c|}{ Estados Unidos Mexicanos } \\
\hline & \begin{tabular}{c|} 
Sin \\
incidentes \\
de violencia
\end{tabular} & $\%$ & \begin{tabular}{c|} 
Con \\
incidentes de \\
violencia $^{1}$ \\
\end{tabular} & $\%$ & \begin{tabular}{|c|} 
Sin \\
incidentes \\
de violencia \\
\end{tabular} & $\%$ & \begin{tabular}{|c|} 
Con \\
incidentes \\
de violencia $^{1}$ \\
\end{tabular} & $\%$ \\
\hline Total & 113923 & 100 & 20576 & 100 & 4662116 & 100 & \begin{tabular}{|r|}
821822 \\
\end{tabular} & 100 \\
\hline $\begin{array}{l}\text { Actual o } \\
\text { anteriormente } \\
\text { unidas }^{2}\end{array}$ & 7128 & 6.3 & 1729 & 8.4 & 777182 & 16.7 & 33742 & 4.1 \\
\hline Solteras & 106795 & 93.7 & 18847 & 91.6 & 3884934 & 83.3 & 788080 & 95.8 \\
\hline
\end{tabular}

${ }^{1}$ Mujeres que declararon haber padecido al menos un incidente de violencia por parte de alguna persona en el ámbito escolar.

2 Incluye a las mujeres actualmente casadas, unidas, separadas, divorciadas o viudas.

Fuente: Cálculos propios a partir de la Encuesta Nacional sobre la Dinámica de las Relaciones en los Hogares, Endireh, 2016. Instituto Nacional de Estadística y Geografía 
En $69.1 \%$ de las adolescentes con estudios de nivel medio superior que sufrieron algún incidente de violencia en el último año se presentaron los más altos porcentajes de violencia sexual, 11.6\%, emocional, $10.5 \%$, y física, $8.3 \%$. Así, entre mayor sea el nivel de escolaridad mayor es la presencia de la violencia sexual, que contrasta con la mayor presencia de violencia física en los menores niveles educativos (cuadro 7, en página siguiente).

A manera de indicador de la desigualdad educativa que enfrentan las adolescentes en Chiapas, mientras en el estado sólo $2.9 \%$ cursa estudios de educación superior, a nivel nacional lo hacen $4.9 \%$. En este bajo porcentaje no se registran incidentes de violencia en el último ańo para las adolescentes de Chiapas como sí sucede entre las adolescentes a nivel nacional.

A decir de Muñoz Izquierdo (citado en Lenin y Favila, 2013: 23), la desigualdad educativa se da cuando no se cumplen en una sociedad la igualdad de condiciones para el ingreso al sistema educativo y la obtención de resultados para quienes pertenecen a todos los estratos sociales. Entonces, hablamos de desigualdad educativa "cuando existe la exclusión de algunos, sean individuos o colectivos, del acceso a las oportunidades educativas, así como de la permanencia y el éxito en el sistema escolar."

Otro indicador de desigualdad educativa lo constituye la mayoritaria asistencia escolar de adolescentes no hablantes de lengua indígena. ${ }^{10}$ Así, mientras 7 de cada 10, 69.5\%, mujeres de 15 a 19 años que asistieron a la escuela en el último año en Chiapas era mestiza, sólo 3 de cada 10 hablaba lengua indígena, HLI. De 30.5\% de adolescentes HLI que sí asistieron a la escuela durante el último año, 5.5\% fue víctima de violencia sexual, $5.3 \%$ de violencia emocional, y $2.3 \%$ de violencia física. A nivel nacional, las adolescentes HLI para el mismo periodo de referencia registraron mayor incidencia de violencia sexual, $9.8 \%$, seguida por la violencia física, $7.1 \%$, y la violencia emocional, 6.3\%.

\footnotetext{
${ }^{10}$ La muestra sin expandir para el estado de Chiapas de las adolescentes de 15 a 19 años que declaran hablar alguna lengua indígena es 103; y las que no la hablan, 228.
} 


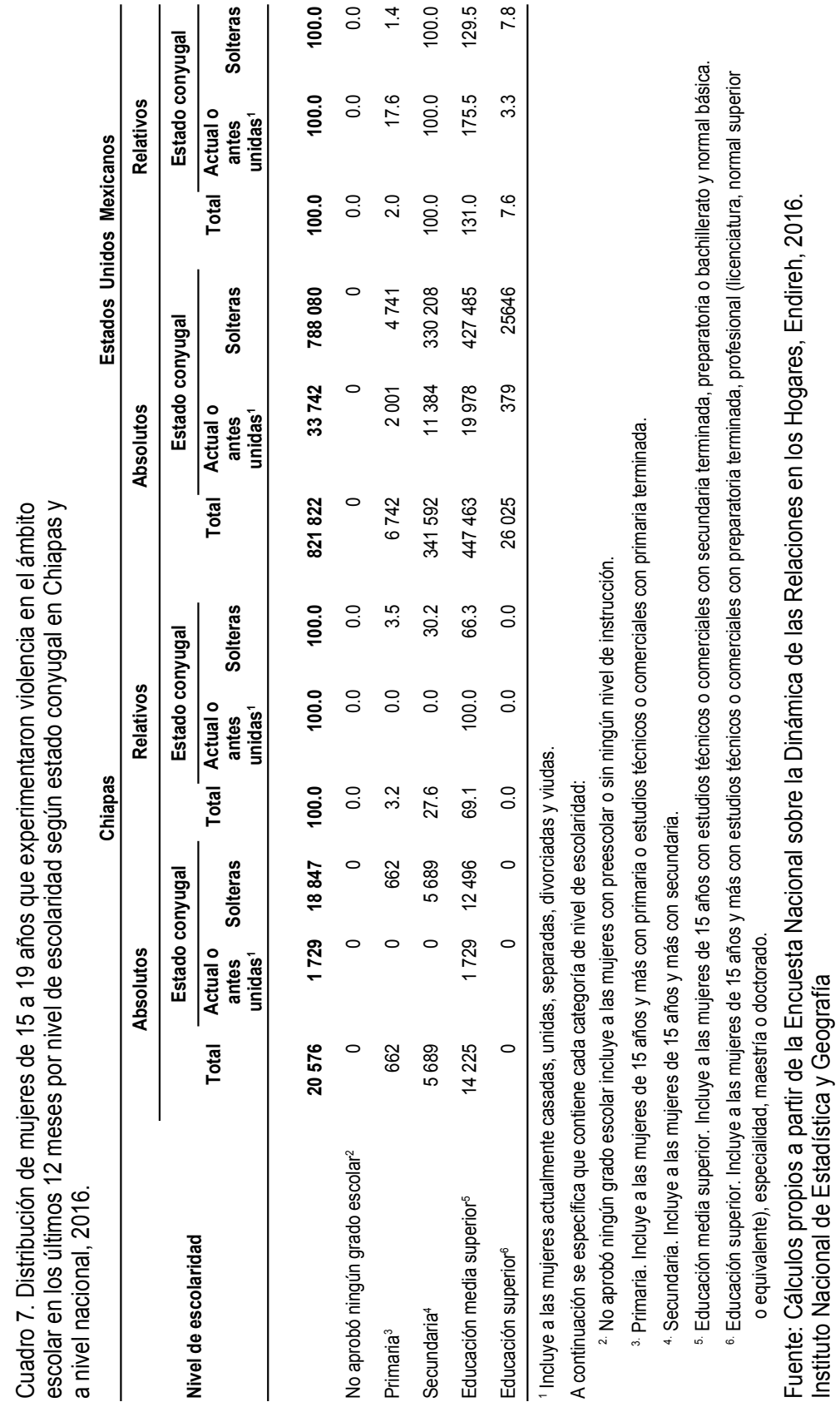


Llama la atención que entre las adolescentes HLI en Chiapas la violencia emocional sea casi tan frecuente como la violencia sexual, mientras que entre las adolescentes no HLI la violencia emocional, 5.6\%, es la menos frecuente en comparación con la violencia física, 8.5\%, y la violencia sexual, $10.7 \%$. Esta presencia de violencia emocional hacia las adolescentes HLI en Chiapas podría estar revelando la complejidad de la intersección de la violencia de género y la discriminación étnica en los ámbitos escolares (cuadro 8).

Cuadro 8. Distribución de adolescentes de 15 a 19 años por condición étnica según condición y tipo de violencia en el ámbito escolar en los últimos 12 meses en Chiapas y a nivel nacional, 2016.

\begin{tabular}{|l|c|c|c|c|c|c|}
\hline \multicolumn{5}{|c|}{ Si habla alguna lengua indigena y/o se considera indígena } \\
\hline & \multirow{2}{*}{$\begin{array}{c}\text { Sin } \\
\text { incidentes de } \\
\text { violencia }\end{array}$} & \multicolumn{4}{|c|}{ Con incidentes de violencia } \\
\cline { 4 - 7 } & Total $^{2}$ & \multicolumn{3}{|c|}{ Tipo de violencia } \\
\cline { 5 - 7 } & & Emocional & Física & Sexual \\
\hline Chiapas & 36145 & 4829 & $11.80 \%$ & $5.30 \%$ & $2.30 \%$ & $5.50 \%$ \\
\hline $\begin{array}{l}\text { Estados } \\
\text { Unidos } \\
\text { Mexicanos }\end{array}$ & 1087765 & 141762 & $11.50 \%$ & $5.10 \%$ & $5.50 \%$ & $6.20 \%$ \\
\hline
\end{tabular}

\begin{tabular}{|c|c|c|c|c|c|c|}
\hline \multicolumn{7}{|c|}{ No habla alguna lengua indígena y no se considera indígena } \\
\hline & \multirow{4}{*}{\begin{tabular}{|c|c|}
$\begin{array}{c}\text { in } \\
\text { incidentes de } \\
\text { violencia }\end{array}$ \\
77788
\end{tabular}} & \multicolumn{5}{|c|}{\begin{tabular}{|c|} 
Con incidentes de violencia \\
${ }^{1}$ \\
\end{tabular}} \\
\hline & & \multirow{2}{*}{\multicolumn{2}{|c|}{ Total $^{2}$}} & \multicolumn{3}{|c|}{ Tipo de violencia } \\
\hline & & & & Emocional & Física & Sexual \\
\hline Chiapas & & 15747 & $16.80 \%$ & $5.60 \%$ & $8.50 \%$ & $10.70 \%$ \\
\hline $\begin{array}{l}\text { Estados } \\
\text { Unidos } \\
\text { Mexicanos }\end{array}$ & 3574245 & 680060 & $16.00 \%$ & $6.30 \%$ & $7.10 \%$ & $9.80 \%$ \\
\hline
\end{tabular}

${ }^{1}$ Mujeres que declararon haber padecido al menos un incidente de violencia por parte de alguna persona en el ámbito escolar.

${ }^{2}$ La suma de los tipos de violencia no coincide con el total, pues cada mujer pudo haber padecido más de uno.

Fuente: Cálculos propios a partir de la Encuesta Nacional sobre la Dinámica de las Relaciones en los Hogares, Endireh, 2016. Instituto Nacional de Estadística y Geografía 


\section{Lugares donde se perpetran las violencias en el ámbito escolar y la denuncia}

Endireh 2016 registra que los lugares donde las mujeres fueron víctimas de violencia en el ámbito escolar son: la escuela; la calle, parque o lugar público cerca de la escuela; la calle, parque o lugar público lejos de la escuela; el transporte público; una casa particular, u otro. En este sentido, la escuela fue el principal lugar donde la mayoría de las adolescentes, $71.9 \%$, en Chiapas experimentaron violencia en el ámbito escolar el último año, seguida por la calle, parque o lugar público cerca de la escuela, $15.3 \%$, y por la calle, parque o lugar público lejos de la escuela, $12.8 \%$. Casi ocho de cada diez, $78.7 \%$, fue víctima de violencia sexual en la escuela, seguido por siete de cada diez, $72.8 \%$, víctima de violencia física y seis de cada diez, 60.6\%, de violencia emocional. A nivel nacional, ocho de cada diez sufrió violencia en la escuela, $81.7 \%$, mientras que $12.6 \%$ la padeció en la calle, parque o lugar público cerca de la escuela. El principal tipo de violencia del que fueron víctimas las adolescentes a nivel nacional en la escuela fue física, $91.2 \%$, seguido de la violencia emocional, 77.6\%, y la violencia sexual, $77.1 \%$.

Como sucede entre otros grupos de edad, casi la totalidad de las adolescentes en Chiapas y a nivel nacional no denunció ni solicitó ayuda, $99.7 \%$ y 99\%, respectivamente. Sin embargo, es relevante mencionar los motivos de no denuncia que en uno y otro contexto dieron las adolescentes. A nivel nacional poco más de la mitad, 52\%, dijo que no denunció "porque se trató de algo sin importancia que no le afectó”, y la otra mitad se distribuyó entre los otros motivos donde el mayor porcentaje lo registró "por miedo a las consecuencias o a las amenazas", $8.2 \%$, y el menor porcentaje "porque la convencieron de no hacerlo", $1.7 \%$.

En Chiapas, $77.1 \%$ de los motivos de no denuncia se concentró en "porque se trató de algo sin importancia que no le afectó"; $31.7 \%$, por vergüenza, $20.2 \%$; "por miedo a las consecuencias o a las amenazas", $14.8 \%$, y en "no sabía cómo y dónde denunciar”, 10.4\%.

En ambos contextos está presente la normalización y naturalización de los incidentes de violencia además de mecanismos institucionales (Mingo y Moreno, 2015) que inhiben y obstaculizan sistemáticamente 
la denuncia, tales como infundir temor por las consecuencias y proferir amenazas, personas que convencen de no denunciar, y la desinformación sobre cómo y dónde denunciar (cuadro 9).

Cuadro 9. Distribución de adolescentes de 15 a 19 años que han experimentado alguna situación de violencia física y/o sexual en el ámbito escolar a lo largo de la vida por condición de solicitud de apoyo ante una institución o presentación de queja o denuncia ante alguna autoridad y motivos de no solicitud de apoyo o presentación de queja o denuncia en Chiapas y a nivel nacional, 2016

\begin{tabular}{|l|r|r|}
\hline \multicolumn{1}{|c|}{$\begin{array}{c}\text { Condición de solicitud de apoyo o presentación de queja } \\
\text { y motivos de no denuncia }\end{array}$} & Chiapas & $\begin{array}{c}\text { Estados } \\
\text { Unidos } \\
\text { Mexicanos }\end{array}$ \\
\cline { 2 - 3 } & & \\
\hline Total de mujer con incidentes de violencia & 100.0 & 100.0 \\
\hline Solicitó apoyo información o servicios o levantó una queja o denuncia & 6.4 & 1.0 \\
\hline No denunció ni solicitó ayuda & 99.7 & 99.0 \\
\hline Por vergüenza & 20.2 & 7.2 \\
\hline Pensó que no le iban a creer o que le iban a decir que era su culpa & 5.0 & 6.8 \\
\hline Por miedo a las consecuencias o a las amenazas & 14.8 & 8.2 \\
\hline Porque no quería que su familia se enterara & 2.4 & 3.7 \\
\hline Porque la convencieron de no hacerlo & 6.0 & 1.7 \\
\hline Porque se trató de algo sin importancia que no le afectó & 31.7 & 52.0 \\
\hline Porque éstas eran/son las costumbres & 1.6 & 1.9 \\
\hline No sabía cómo y dónde denunciar & 10.4 & 5.6 \\
\hline Porque es una pérdida de tiempo o porque no tenía tiempo & 0.0 & 2.6 \\
\hline No confía en las autoridades del gobierno & 7.7 & 2.6 \\
\hline Otra & 0.0 & 6.7 \\
\hline No especificado & 0.0 & 0.0 \\
\hline No especificado & 0.0 & 0.0 \\
\hline
\end{tabular}

${ }^{1}$ La suma de los motivos por los que no solicitó ayuda ni denunció no coincide con el total, pues cada mujer pudo haber tenido más de un motivo.

Fuente: Cálculos propios a partir de la Encuesta Nacional sobre la Dinámica de las Relaciones en los Hogares, Endireh, 2016. Instituto Nacional de Estadística y Geografía

\section{Conclusiones}

Aunque las principales acciones de violencia en contra de las adolescentes en Chiapas en el ámbito escolar corresponden a un nivel de severidad que podríamos considerar leve y de baja intensidad (Castro y Vázquez, 2008), su importancia recae en que se establecen como hechos normales o naturales; por lo tanto, son invisibilizadas y pasan a formar parte de las reglas del juego que rigen las interacciones sociales de sometimiento y subordinación con sus pares, y de ellas con sus profesores y en menor medida con sus profesoras. 
Si bien no se trata de agresiones severas, sí de acciones efectivas que cumplen la función de reproducir las jerarquías de género y de someter a las reglas de dominación masculina en principio a las mujeres (Villela y Arenas, 2011; Mingo, 2013; Mingo y Moreno, 2015), pero también a quienes muestren rasgos de inconformidad a este orden de género; es decir, hombres y personas LGBT (Castro, 2012).

Que las propias adolescentes consideren mayoritariamente que se trató de algo sin importancia que no les afectó habla de su predisposición a la conformidad con el sometimiento, pero más aún del carácter sistémico de la violencia contra las mujeres que se inicia en la familia de origen, se incorpora como parte del habitus y se reproduce en el ámbito escolar donde otros factores institucionales y sociales contribuyen a la opresión de que son objeto las adolescentes (Castro y Vázquez, 2008).

No existe una cultura de denuncia entre adolescentes en Chiapas que han sufrido violencia en el ámbito escolar, como tampoco existe para otros niveles superiores de escolaridad ni a nivel nacional. Los principales motivos por los que no denuncian las adolescentes en Chiapas revelan por un lado la naturalización, normalización y tolerancia de un ambiente hostil cotidiano (Villela y Arenas, 2011; Mingo, 2013; Mingo y Moreno, 2015) al afirmar que se trató de algo sin importancia y por vergüenza no lo hacen. Por otro lado, muestran los mecanismos institucionales para mantener este ambiente mediante la imposición y aprendizaje del silencio (Mingo y Moreno, 2015) al manifestar miedo a las represalias y consecuencias, que las convencieron de no denunciar, y al no tener conocimiento sobre cómo y dónde denunciar. Así, los agresores, mayoritariamente hombres, quedan en la impunidad apoyados por redes de complicidad institucional e incluso seguramente continúan conviviendo con ellas si es que no se vieron obligadas a abandonar los estudios como consecuencia de la violencia sufrida en la escuela.

Se infieren sentimientos de culpa entre las adolescentes que reportan a partir de los motivos para no denunciar. Así, decir que no denunciaron por vergüenza, $20.2 \%$, o que no querían que su familia se enterara, $2.4 \%$, apunta a que se sienten responsables de la violencia que sufrieron al haber provocado al perpetrador, justificando así su agresión (Villela y Arenas, 2011; Puglisi, 2012). 
Es probable que la naturalización y normalización de la violencia hacia las adolescentes que se infiere a partir de los motivos para no denunciar explique los menores porcentajes de la violencia sexual, física y emocional entre adolescentes de Chiapas respecto a las adolescentes a nivel nacional. Sin embargo, destaca que para el acoso sexual/hostigamiento sexual las adolescentes en Chiapas reportan un porcentaje cuatro veces superior, $3.1 \%$ vs. $0.7 \%$, para el último año como periodo de referencia.

Los resultados revelan como principales perpetradores de la violencia sexual, física y emocional contra las adolescentes en el último año a sus compañeros; es decir, se trata de una violencia entre pares. Lo anterior cobra importancia en tanto que indicador de la socialización violenta de los hombres adolescentes. Los maestros violentan sexual y emocionalmente a las adolescentes ostentando una relación de jerarquía y de privilegio masculino.

En términos generales, los resultados revelan un incremento de los diferentes tipos de violencia en el ámbito escolar cuando el periodo de referencia es a lo largo de la vida mostrando así la presencia de diferentes manifestaciones de violencia de género en los niveles educativos inferiores al que cursaban al momento de la entrevista. Destacan aquellas situaciones donde el porcentaje se duplica e incluso se incrementa considerablemente: intimidación y acecho, $0.9 \%$ vs. $1.6 \%$; abuso sexual, $1 \%$ vs. $2.1 \%$; acoso sexual/hostigamiento sexual, $3.1 \%$ vs. $18.5 \%$, y de manera específica la han atacado o agredido con un cuchillo, navaja o arma de fuego, $0 \%$ vs. $1 \%$.

Los resultados para adolescentes HLI y no HLI muestran mayor presencia de violencia entre las segundas. El que sólo 30.5\% de las adolescentes encuestadas fuera HLI podría explicar este resultado, pero también sería muy útil un análisis que permitiera identificar, a partir de los motivos para no denunciar, en qué grupo están más naturalizadas y normalizadas las diferentes violencias de género hacia las mujeres. Sin embargo, como ya se mencionó, la presencia de violencia emocional con la misma frecuencia que la violencia sexual entre las adolescentes HLI en Chiapas sugiere la presencia de experiencias interseccionadas de violencia de género y discriminación étnica como futura línea de investigación. 
El hecho de que entre las adolescentes con mayor escolaridad en Chiapas se presenten los mayores porcentajes de violencia sexual, emocional y física podría apuntar a que existe mayor registro, debido a que se cuestiona la normalización y naturalización de la violencia de género hacia las mujeres. Así también, sugiere que la violencia física ocurre en los primeros años de formación escolar.

Materia de investigaciones futuras es explorar la bidireccionalidad de la violencia para "no concentrarse solamente en la violencia que las mujeres sufren, sino también en la que ellas ejercen (Castro, 2016). La investigación a realizarse en este sentido permitiría comprender la frecuencia de la violencia física perpetrada por otras adolescentes en Chiapas, así como precisar cuánta de ésta es violencia de género y cuánta perpetrada por otros motivos diferentes al género.

Asimismo, el análisis de la violencia de género en el ámbito escolar resulta de suma importancia no sólo por las consecuencias individuales que genera, también por las posibles consecuencias sociales. El ausentismo y la deserción escolar en relación con la violencia de género tienen escaso registro estadístico; pero si se toma en cuenta que Chiapas es una de las entidades con menor presencia de mujeres en la educación media superior, se puede inferir una importante veta por explorar en el futuro.

Los resultados de Endireh analizados en este artículo no reportan la existencia de una relación de noviazgo entre las adolescentes y sus victimarios en el ámbito escolar, y en tanto que una gran mayoría de las que reportan incidentes de violencia son solteras y víctimas de sus compañeros sería importante saber cuántos de estos incidentes tendrían características de violencia en el noviazgo.

Finalmente, los resultados aquí analizados nos enfrentan al reto conceptual de diferenciar la violencia de género de otras formas de violencia hacia las mujeres asumiendo que no toda la violencia contra las mujeres es violencia de género. Se revela también la imperante necesidad de investigar los cruces entre el género y otras condiciones sociales, además del estado conyugal, la escolaridad y la condición étnica, tales como la discapacidad y la preferencia sexual. 


\section{Bibliografía citada}

Álvarez-Solís, Rubén M. y Marcela del P. Vargas-Vallejo, 2002, "Violencia en la adolescencia”, Salud en Tabasco, vol. 8, núm. 2, pp. 95-98, agosto.

Arias-Gallegos, Walter L., 2013, "Agresión y violencia en la adolescencia: la importancia de la familia", Revista Avances en Psicología, vol. 21, núm. 1, pp. 23-34.

Ayala-Carrillo, María del Rosario, 2015, "Violencia escolar: un problema complejo”, Ra Ximhai, vol. 11, núm. 4, pp. 493-509.

Castillo-Pulido, Luis E., 2011, "El acoso escolar origen y manifestaciones a la pregunta por el sentido que le otorgan los actores", Magis. Revista Internacional en Estudios de Educación, vol. 4, núm. 8, pp. 415-428, julio-diciembre.

Castro, Roberto, 2012, "Problemas conceptuales en el estudio de la violencia de género. Controversias y debates a tomar en cuenta”, en Norma Baca Tavira y Graciela Vélez Bautista (coordinadoras), Violencia, género y la persistencia de la desigualdad en el Estado de México, Mnemosyne, Buenos Aires, pp. 17-38.

Castro, Roberto, 2016, "Lo que sabemos y lo que ignoramos", Nexos, 1 de junio, [en línea] disponible en https://www.nexos.com. $\mathrm{mx} /$ ?p=28505 [fecha de consulta: 29 de junio de 2018].

Castro, Roberto y Verónica Vázquez, 2008, "La universidad como espacio de reproducción de la violencia de género. Un estudio de caso en la Universidad Autónoma Chapingo, México", Estudios Sociológicos, vol. 26, núm. 78, pp. 587-616.

Comisión Nacional de Derechos Humanos, CNDH, 2014, Recomendación General no. 21 sobre la prevención, atención y sanción de casos de violencia sexual en contra de las niñas y los niños en centros educativos, CNDH, México.

Diario Oficial de la Federación, DOF, 2009, Ley General de Acceso de las Mujeres a una vida libre de Violencia, Poder Judicial del Estado de Chiapas, México, disponible en http://www. poderjudicialchiapas.gob.mx/forms/archivos/ddc2ley-generalde-acceso-de-las-mujeres-a-una-vida-libre-de-violencia.pdf [fecha de consulta: 20 de junio de 2018]. 
di Napoli, Pablo, 2018, "Una mirada a las investigaciones cualitativas sobre jóvenes, conflictos y violencia en las escuelas secundarias en América Latina”, EntreDiversidades, núm. 10, pp. 9-37.

Dunezat, Xavier, 2017, “Sexo, raza, clase y etnografía de los movimientos sociales. herramientas metodológicas para una perspectiva interseccional", Revista de Investigaciones Feministas, vol. 8, núm. 1, pp. 95-114.

Frías, Sonia, 2012, "Violencia contra las mujeres mexicanas en los ámbitos familiar, educativo, laboral, comunitario e institucional: evidencia a partir de las encuestas", en Roberto Castro y Florinda Riquer (coordinadores), Estudio nacional sobre las fuentes, origenes y factores que producen y reproducen la violencia contra las mujeres, Estudios Nacionales, tomo I, vol. II, CONAVIM, México, pp. 45-224.

Instituto Nacional de Estadística y Geografía, Inegi, 2015, Panorama de violencia contra las mujeres en Quintana Roo: ENDIREH 2011, Inegi, Ciudad de México, México.

Instituto Nacional de Estadística y Geografía, Inegi, 2016, Encuesta Nacional sobre Disponibilidad y Uso de las Tecnologías de la Información en los Hogares, ENDUTIH 2015, Inegi, México.

Instituto Nacional de Estadística y Geografía, Inegi, 2017, Encuesta Nacional sobre la Dinámica de las Relaciones en los Hogares 2016, Inegi, Ciudad de México, México.

Lenin, José César y Antonio Favila, 2013, "La desigualdad de la educación en México, 1990-2010: el caso de las entidades federativas", Revista Electrónica de Investigación Educativa, vol. 15, núm. 2, pp. 21-33.

Martínez, José Saturnino, 2017, "El habitus. Una revisión analítica", Revista Internacional de Sociología, vol. 75, núm. 3, p. e074.

Mingo, Araceli, 2013, "Cuatro grados bajo cero. Mujeres en la universidad", en Carolina Argoff, Irene Casique y Roberto Castro (coordinadores), Visible en todas partes. Estudios sobre violencia contra mujeres en múltiples ámbitos, CRIM UNAM, Miguel Ángel Porrúa, México, pp. 103-118. 
Mingo, Araceli y Hortencia Moreno, 2015, "El ocioso intento de tapar el sol con un dedo: violencia de género en la universidad", Perfiles Educativos, vol. XXXVII, núm. 148, pp. 138-155.

Organización Naciones Unidas, ONU, 1994, "Asamblea general A/ RES/48/104", Declaración sobre la eliminación de la violencia contra la mujer, disponible en http://www.un.org/es/comun/ docs/?symbol=A/RES/48/104\&Lang=S [fecha de consulta: 20 de junio de 2018].

Platero, Raquel (Lucas), 2014, “¿Es el análisis interseccional una metodología feminista y queer?”, en Irantzu Mendia et al., Otras formas de (re)conocer: Reflexiones, herramientas y aplicaciones desde la investigación feminista, Instituto Hegoa, Universidad del País Vasco, España, pp. 79-95.

Puglisi, Bárbara, 2012, Las escuelas como escenarios en los que se producen y reproducen violencias contra niños, niñas y adolescentes, Instituto Latinoamericano de Investigaciones Sociales ILDIS, Caracas, Venezuela.

Sales, Gelabert, 2017, "Repensando la interseccionalidad desde la teoría feminista”, AGORA. Papeles de Filosofía, vol. 36, núm. 2, pp. 229-256.

Secretaría de Educación Media Superior, SEMS, 2014, Tercer Encuesta Nacional sobre Exclusión, Intolerancia y Violencia en las Escuelas de Educación Media Superior, SEP, México.

Secretaría de Educación Pública, SEP, 2013, Manual para prevenir los riesgos del abandono escolar, SEP, México.

Villela Esther y Guillermina Arenas, 2011, "Acoso sexual a estudiantes de enfermería durante la práctica clínica: una mirada de género”, Rayuela. Revista Iberoamericana sobre niñez y juventud en lucha por sus derechos, núm. 4, pp. 41-45.

Wackerly, Dennis, William Medndenhall y Richard Scheaffer, 2002, Estadistica Matemática con Aplicaciones, Thompson, México. 


\section{Anexo}

Anexo 1. Distribución de adolescentes de 15 a 19 por condición, tipo, clase y situación de violencia en el ámbito escolar según periodo de referencia, 2016, Chiapas.

\begin{tabular}{|c|c|c|c|c|}
\hline \multirow{3}{*}{$\begin{array}{c}\text { Condición, tipo, clase y situación de } \\
\text { violencia }\end{array}$} & \multicolumn{2}{|c|}{ Absolutos } & \multicolumn{2}{|c|}{ Valor $p$} \\
\hline & \multicolumn{2}{|c|}{ Periodo de referencia } & \multicolumn{2}{|c|}{ Periodo de referencia } \\
\hline & $\begin{array}{l}\text { A lo largo de } \\
\text { la vida }\end{array}$ & $\begin{array}{l}\text { En los últimos } \\
12 \text { meses }\end{array}$ & $\begin{array}{l}\text { A lo largo de } \\
\text { la vida }\end{array}$ & $\begin{array}{l}\text { En los últimos } \\
12 \text { meses }\end{array}$ \\
\hline Total de mujeres que asistieron a la escuela & 233166 & 134499 & 0.000 & 0.000 \\
\hline Sin incidentes de violencia escolar & 189973 & 113923 & 0.000 & 0.000 \\
\hline Con incidentes de violencia escolar & 43193 & 20576 & 0.000 & 0.000 \\
\hline Violencia emocional & 15630 & 7406 & 0.000 & 0.000 \\
\hline Degradación / Acoso emocional & 13693 & 6155 & 0.014 & 0.023 \\
\hline Intimidación y acecho & 3728 & 1251 & 0.018 & 0.021 \\
\hline Violencia física & 21810 & 8922 & 0.000 & 0.000 \\
\hline Violencia sexual & 22005 & 12308 & 0.000 & 0.000 \\
\hline Intimidación sexual & 17893 & 10630 & 0.000 & 0.000 \\
\hline Acoso sexual / Hostigamiento sexual & 4937 & 4167 & 0.025 & 0.043 \\
\hline Abuso sexual & 4801 & 1408 & 0.030 & 0.031 \\
\hline Violación e intento de violación & 1359 & 589 & 0.067 & 0.053 \\
\hline
\end{tabular}

Fuente: Cálculos propios a partir de la Encuesta Nacional sobre la Dinámica de las Relaciones en los Hogares,

Endireh, 2016. Instituto Nacional de Estadística y Geografía 
Violencia de género experimentada en el ámbito escolar...
Angélica A. Evangelista García Sarai Miranda Juárez

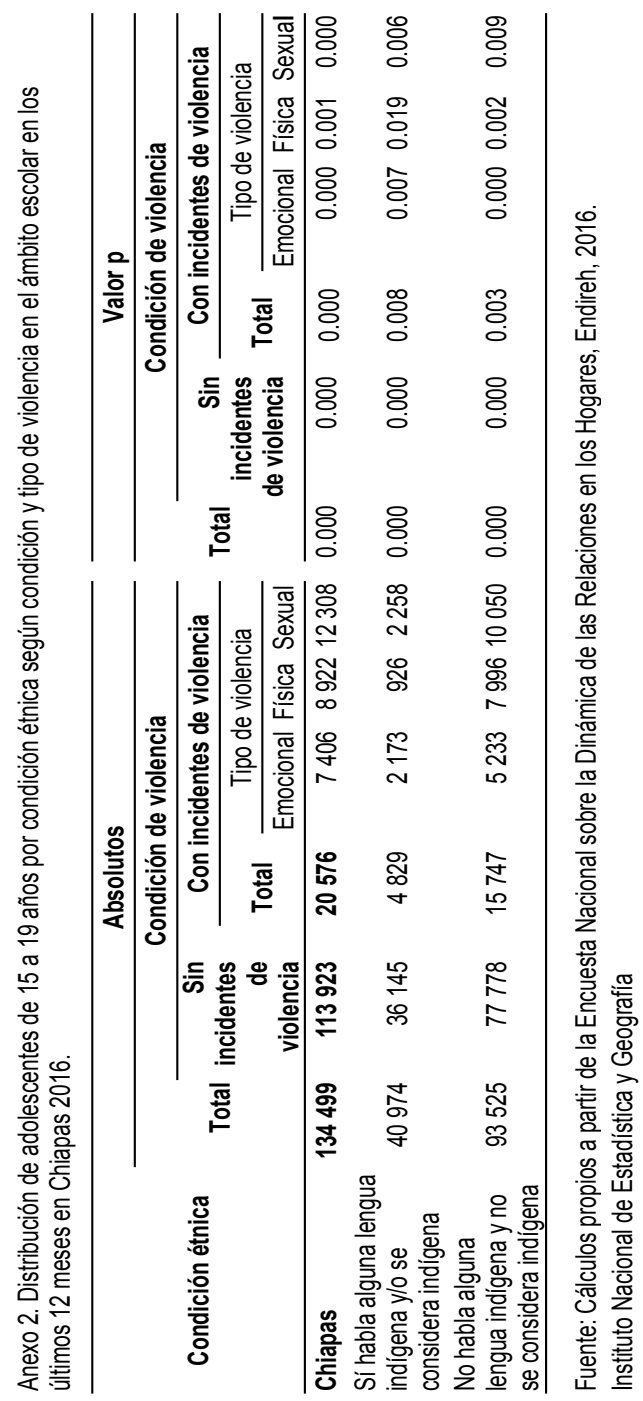

julio-diciembre 2018, núm. 11 